\title{
Screening tests for glycosaminoglycans in urine: experience from regional interlaboratory surveys
}

\author{
J M RATTENBURY, E WORTHY, JOYCE C ALLEN \\ From the Department of Chemical Pathology, Children's Hospital, Sheffield
}

SUMMARY Three urine samples were distributed to laboratories in the Trent and Yorkshire regions to assess their ability to detect glycosaminoglycans. Satisfactory results were obtained for samples from patients with Hunter's and Morquio's diseases but six of 14 laboratories reporting a result for a Sanfilippo sample missed the abnormality. Replies to a subsequent questionnaire showed that unsuccessful laboratories were not using recommended screening methods, that they lacked experience in testing for these diseases, and that rationalisation of such screening services may be indicated.

The glycosaminoglycan (GAG) storage diseases (mucopolysaccharidoses) are a group of inherited metabolic defects whose usual manifestations are abnormalities of skeletal or neurological development or a combination of both due to the intracellular accumulation of complex macromolecules. Definitive diagnosis of these diseases requires the demonstration of reduced activities of specific lysosomal enzymes in leucocytes or cultured fibroblasts, but these assays are only available in a few specialist centres. Selection of patients with suspected GAG storage diseases for enzyme analysis depends on the results from clinical and radiological investigations and from the screening tests for excessive urinary GAG excretion, which may be performed by non-specialist laboratories.

The basis of most urinary GAG screening tests is the binding of an appropriate dye or flocculating agent to the acidic GAG macromolecules to give a visible reaction. Dye binding reagents include toluidine or alcian blue, and flocculation tests may use albumin, cetyltrimethylammonium bromide, or cetylpyridinium chloride. Separation procedures such as electrophoresis or thin layer chromatography may be used to identify particular classes of GAG. Many modifications to GAG screening tests have been published, and refinements include quantifiable results related to urine concentration and the age of the patient. GAG screening methods referred to in this report are listed in the footnote to table 2 .

To enable laboratories to assess their performance in metabolic screening tests, interlaboratory surveys (quality assurance exercises) have been organised since

Accepted for publication 7 April 1988
1981 in the Trent and Yorkshire Health Authority regions. Laboratories participating in these surveys were situated in general or teaching hospitals serving a total population of $8 \cdot 2$ million. Most, but not all, of the larger laboratories in the regions perform GAG screening tests; the decision whether to provide them depending on such factors as available expertise in the laboratory and the proximity of a suitable centre to which to refer samples.

Forty samples were distributed for the regional interlaboratory surveys and three of them were from patients with GAG storage diseases. The first two of these samples contained pronounced excesses of GAG which were detected by all laboratories returning a result. The third sample had only a moderate increase in GAG, and several laboratories failed to detect the abnormality. Information given in the returns for the last sample indicated that success in detecting the GAG abnormality depended on the GAG screening method used. A follow up questionnaire was sent to participants in the survey to request information about their methods and test strategies when screening for GAG disease. The results of this exercise are presented in this paper.

\section{Material and methods}

The first survey specimen to contain abnormal GAG was distributed to 10 laboratories in the Trent region in April 1983. It came from a 9 year old girl with Morquio's disease (GAG disease type IV) and had been stored for some years at $-20 \mathrm{C}$. This girl was noted to have deformed lower limbs at 6 months of age and thereafter progressively developed the severe clinical and radiological features of this condition. 
Biochemical confirmation of the disorder was obtained by the detection of increased GAG in urine (three times the upper limit of normal) and by an appropriate electrophoretic pattern of increased keratan sulphate excretion (assay performed by the Institute of Child Health, London).

The second specimen was sent to 24 laboratories in the Trent and Yorkshire regions in 1984. It was a pooled collection of urine samples obtained at a mean age of 12 years from a boy with Hunter's disease (GAG type IIB). He was noted to have leg deformities at $3 \frac{1}{2}$ years of age and a more generalised dysplasia was detected on examination. A radiological survey indicated changes consistent with GAG disease and this was confirmed by a urinary GAG excretion more than three times the upper limit of normal, an appropriate electrophoretic pattern (assays performed at Birmingham Children's Hospital), and a much reduced serum iduronate-2-sulphate sulphatase activity (assay performed at University Hospital, Cardiff). The GAG type was characterised as Hunter IIB on account of the relatively mild clinical features including normal intelligence. Urine samples from this patient were stored at $-20^{\circ} \mathrm{C}$ for some years, thawed the day before distribution, mixed well and divided into aliquots for dispatch. Increased GAG and appropriate electrophoretic excretion patterns in the samples were confirmed by the organising laboratory.

The third specimen came from a three year old boy with Sanfilippo disease and was distributed in February 1987. He had transient neonatal hyperbilirubinaemia but achieved normal milestones up to 18 months of age. Thereafter he was difficult to potty train, slow to speak, and appeared to have hearing difficulties. At 2 years a hair line skull fracture was detected, he was considered to be hyperactive, and slept little before 3 years of age. Sanfilippo disease type IIIA was diagnosed by showing reduced sulphamidase activity in cultured fibroblasts (assay performed by the Willink Biochemical Genetics Unit, Royal Manchester Children's Hospital). Urine samples from this child were reclaimed from nappies soiled only with urine; sterilised by graded filtration, and stored deep frozen without preservative. For distribution, it was thawed overnight, mixed well, divided into suitable portions and sent by first class post with the information: "boy 3 years old, mental retardation, disturbed sleep".

The standardised reporting forms sent out with the survey samples asked laboratories to treat them as if they were from actual patients under investigation. They gave the age and sex of the patient from whom the sample had been obtained and a brief clinical summary such as might be expected on a laboratory request form. Participants were asked to: (a) record their findings under the headings "screening test", "chromatography", and "other tests", (b) provide a presumptive diagnosis; and (c) select two from eight listed possible courses of action such as referral to clinical staff or to a reference laboratory at an appropriate degree of urgency. Two full working weeks were allowed for testing the specimen and returning results to the organisers. Summaries of results from each exercise were returned to participants and discussed at regional meetings for heads of departments. Four months after distribution of the last sample, a questionnaire was sent to all participating laboratories requesting details of their methods and testing strategies (table 1).

\section{Results}

All eight laboratories which reported a GAG result for the first sample (Morquio's disease) and all 17 of those reporting a GAG result for the second sample (Hunter's disease) detected these abnormalities. The third sample was distributed to 24 laboratories of whom 14 reported results of GAG testing. Eight $(57 \%)$ of these laboratories reported a correct result but $6(43 \%)$ missed the abnormality. Twenty one $(88 \%)$ replies were received to the 24 questionnaires sent out. Eighteen laboratories reported that they performed GAG testing and three referred all their samples to another centre. Thirteen of the respondents reported results for the third sample; thus five laboratories claiming to screen for GAG did not report on it and gave no reason. One laboratory which reported on this sample did not reply to the questionnaire. It was apparent from the returns for survey samples and the replies to the questionnaire that GAG testing was performed by 19 laboratories in the two regions.

The questionnaire respondents each screened between six and 300 samples (mean 59) in 1986. Over the previous five years they had detected 16 cases of GAG disease, nine of which were reported by one centralised laboratory. Another laboratory detected four cases and three laboratories had detected one case each. Thus 13 laboratories screening for GAG disease in

Table I Summary of questions asked in GAG screening questionnaire

\footnotetext{
Laboratory address

Do you perform GAG screening tests?

To whom do you refer:

a) all samples, b) those for follow up testing?

Number of GAG tests performed in 1986 and how frequently?

State GAG tests used and strategy such as

first line tests, second line (follow up tests)

Method of standardisation

Positive controls: type, frequency of use

Correction for urine concentration a) in samples, b) for results Use of age related reference ranges

Number of patients with GAG disease detected in past

five years and GAG type
} 
Table 2 Strategies for GAG testing (No of laboratories in parentheses)

\begin{tabular}{|c|c|c|c|c|c|c|c|c|}
\hline & \multirow{2}{*}{$\begin{array}{l}\text { Mean No of } \\
\text { GAG screens } \\
\text { in } 1986\end{array}$} & \multirow{2}{*}{$\begin{array}{l}\text { Initial } \\
\text { screening } \\
\text { method }\end{array}$} & \multirow{2}{*}{$\begin{array}{l}\text { Second or } \\
\text { subsequent } \\
\text { method }\end{array}$} & \multirow{2}{*}{$\begin{array}{l}\text { Standards } \\
\text { used? }\end{array}$} & \multirow{2}{*}{$\begin{array}{l}\text { Positive } \\
\text { control } \\
\text { used? }\end{array}$} & \multicolumn{2}{|c|}{ Creatinine correction } & \multirow{2}{*}{$\begin{array}{l}\text { Age related } \\
\text { reference } \\
\text { ranges used? }\end{array}$} \\
\hline & & & & & & (to samples) & (in calculation) & \\
\hline $\begin{array}{l}\text { Laboratories returning } \\
\text { a correct result for } \\
\text { sample } 3 \text { ( } 7 \text { ) } \\
\text { (One laboratory did } \\
\text { not reply to the } \\
\text { questionnaire) }\end{array}$ & 89 & $\begin{array}{l}\text { CPC(5) } \\
\text { CPC + CTAB(1) } \\
Q A B(1)\end{array}$ & $\begin{array}{l}\text { QAB(2) } \\
\text { EPH(1) } \\
\text { TLC(1) } \\
\text { none(3) }\end{array}$ & $\begin{array}{l}\text { Yes(7) } \\
\text { No(0) }\end{array}$ & $\begin{array}{l}\text { Yes(3) } \\
\text { No(4) }\end{array}$ & $\begin{array}{l}\text { Yes(3) } \\
\text { No(2) } \\
\text { No reply(2) }\end{array}$ & $\begin{array}{l}\text { Yes(7) } \\
\text { No(0) }\end{array}$ & $\begin{array}{l}\text { Yes(7) } \\
\text { No(0) }\end{array}$ \\
\hline $\begin{array}{l}\text { Laboratories returning } \\
\text { an incorrect result } \\
\text { for sample } 3 \text { (6) }\end{array}$ & 35 & $\begin{array}{l}\text { TBS }(1) \\
\text { TBS + CTAB(2) } \\
\text { ABS(1) } \\
\text { AA(2) }\end{array}$ & $\begin{array}{l}\text { QAB(1) } \\
\text { CPC(1) } \\
\text { AA(1) } \\
\text { none(3) }\end{array}$ & $\begin{array}{l}\text { Yes(1) } \\
\text { No(5) }\end{array}$ & $\begin{array}{l}\text { Yes(4) } \\
\text { No(2) }\end{array}$ & $\begin{array}{l}\text { Yes(1) } \\
\text { No(5) }\end{array}$ & $\begin{array}{l}\text { Yes(2) } \\
\text { No(2) } \\
\text { No reply(2) }\end{array}$ & $\begin{array}{l}\text { Yes(1) } \\
\text { No(5) }\end{array}$ \\
\hline $\begin{array}{l}\text { Laboratories returning } \\
\text { no result for } \\
\text { sample } 3(5)\end{array}$ & 43 & $\begin{array}{l}\mathrm{CPC}(1) \\
\mathrm{CPC}+\mathrm{ABS}(1) \\
\mathrm{CPC}+\mathrm{QAB}(1) \\
\mathrm{TBS}(1) \\
\mathrm{EPH}(1)\end{array}$ & $\begin{array}{l}\text { QAB(1) } \\
\text { none(4) }\end{array}$ & $\begin{array}{l}\text { Yes(5) } \\
\text { No(0) }\end{array}$ & $\begin{array}{l}\text { Yes(2) } \\
\text { No(3) }\end{array}$ & $\begin{array}{l}\text { Yes(3) } \\
\text { No(2) }\end{array}$ & $\begin{array}{l}\text { Yes(3) } \\
\text { No(1) } \\
\text { No reply(1) }\end{array}$ & $\begin{array}{l}\text { Yes(5) } \\
\text { No(1) }\end{array}$ \\
\hline
\end{tabular}

CPC, cetylpyridinium chloride/citrate'; CTAB, cetyltrimethylammonium bromide ${ }^{2} ; \mathrm{ABS}$, alcian blue spot test ${ }^{3} ;$ QAB, quantitative alcian blue assay $^{4}$; TBS, toluidine blue spot test ${ }^{5}$; AA, acid albumin ${ }^{67}$; EPH, one dimensional electrophoresis ${ }^{8}$; TLC, thin layer chromatography'.

these regions had detected no cases over the past five years. Strategies for GAG testing and the methods used by laboratories which replied to the questionnaire are given in table 2 .

\section{Discussion}

All laboratories which indicated in their answers to the questionnaire that they used cetylpyridinium chloride/ citrate (CPC) or quantitative alcian blue assay (QAB) (for references to methods and the full list of abbreviations see footnote to table 2) as their first stage screening test, successfully detected the abnormality in the Sanfilippo sample. Testing strategies which failed to detect the abnormality are shown in table 2, and all included toluidine blue spot test (TBS), cetyltrimethylammonium bromide (CTAB), alcian blue spot test (ABS) or acid albumin (AA) as the primary screening method. Presumably the two laboratories which failed to detect the abnormality but had CPC or $\mathrm{QAB}$ as their second stage test did not progress beyond an initial negative screening result. One laboratory successfully detected the increased GAG in the Sanfilippo sample with a CPC test but their CTAB result was negative. Five laboratories admitted to GAG screening in the questionnaire but did not return a result for the Sanfilippo sample, although three of these laboratories had reported on previous GAG survey samples. No explanation was forthcoming for this inconsistency.

The results of these surveys confirm previous findings in individual laboratories that GAG abnormalities in specimens from Sanfilippo patients may be missed by non-quantitative screening methods. $^{1011}$ Guidelines for GAG screening ${ }^{10}$ recommend that CPC or QAB methods be used to avoid false negative results. Quantitative methods (CPC or QAB) make allowance for variations in urine concentration (by reference to specific gravity or creatinine concentration) and provide age related reference ranges. It is also recommended that specimens should not be early morning collections, have creatinine concentrations of not less than 1.5 $\mathrm{mmol} / \mathrm{l}$ and should not be infected. ${ }^{1012}$

It is apparent (table 2) that laboratories which successfully detected the Sanfilippo sample made greater use of GAG standards, creatinine corrections, and age related reference ranges than the unsuccessful laboratories. In most cases the use of such refinements would be dictated by the published method rather than result from the laboratory opting to employ them. By way of contrast, positive control samples were used by a greater proportion of laboratories which did not detect the Sanfilippo abnormality than those that did. Possibly, these controls provided false security as two of those used by the unsuccessful laboratories were from type I patients, one was a normal urine sample supplemented with chondroitin sulphate, and one laboratory used controls of an unspecified type.

The GAG in the Sanfilippo sample may have become reduced or changed by the method of sample collection and filtration. Nevertheless, when tested by the organising laboratory prior to distribution the GAG values were one and a half times the upper limit of normal and the abnormality was detected by all laboratories using the recommended GAG methods.

The mean number of GAG tests performed in 1986 by the successful laboratories (table 2) was more than twice the number performed by the unsuccessful laboratories or by those returning no results. Of the 16 cases of GAG disease detected in the past five years by respondents to the questionnaire, 14 were reported by 
laboratories which detected the abnormality in the Sanfilippo sample. Therefore, not only were unsuccessful laboratories less practised at performing GAG tests, they also had little or no experience of detecting GAG disease. The 16 cases of GAG disease reported in the questionnaire would be an underestimate of the prevalence of these diseases in the two regions as they did not include samples sent directly to reference centres.

It is apparent from this exercise that in spite of published advice for GAG testing, ${ }^{10}$ laboratories continue to use inadequate methods. In two health regions more than a dozen different GAG testing strategies were found to be in use and if representative of the whole country suggest that a considerable number of laboratories may be using unsatisfactory GAG methods. Since 1986 a national quality assurance scheme for GAG screening methods has been organised from Bristol Maternity Hospital and the results from these distributions should provide a nationwide overview of the state of GAG testing. Until these results are available, the conclusion from the surveys and questionnaire conducted in the Trent and Yorkshire regions must be that screening for GAG disease should be by recommended quantitative methods. It could also be argued that screening success would be enhanced by the referral of samples to fewer centres as the experience of other quality assurance schemes (such as phenylketonuria (PKU) screening) is that overall performance improves when less successful laboratories (usually with smaller workloads) withdraw from testing so that screening is carried out in larger numbers at fewer centres.

We thank Mr K R Johnson of Staincliffe Hospital, Dewsbury, West Yorkshire, for providing the sample from the patient with Sanfilippo disease and Mrs Elaine Singleton for typing the manuscript.

\section{References}

1 Pennock CA. A modified screening test for glycosaminoglycan excretion. J Clin Pathol 1969;22:379-80.

2 Renuart AW. Screening for inborn errors of metabolism associated with mental deficiency or neurologic disorders or both. $N$ Engl J Med 1966;274:384-7.

3 Carson NAJ, Neill DW. Metabolic abnormalities detected in a survey of mentally backward individuals in Northern Ireland. Arch Dis Child 1962;37:505-13.

4 Whiteman $P$. The quantitative determination of glycosaminoglycans in urine with alcian blue $8 \mathrm{GX}$. Biochem $J$ 1973;13:351-7.

5 Berry AK, Spinanger J. A paper spot test useful in the study of Hunter's syndrome. J Lab Clin Med 1960;55:136-9.

6 Dorfman A. Studies on the biochemistry of connective tissue. Pediatrics 1958;22:576-89.

7 Carter CH, Wan ATW, Carpenter DG. Commonly used tests in the detection of Hurler's Syndrome. Pediatrics 1968;73: 217-21.

8 Wessler E. Analytical and preparative separation of acidic glycosaminoglycans by electrophoresis in barium acetate. Analyt Biochem 1968;26:439-44.

9 Humbel R, Chamoles NA. Sequential thin layer chromatography of urinary acid glycosaminoglycans. Clin Chim Acta 1972;40:290-3.

10 Pennock CA. Investigation of mucopolysaccharides. ACP Broadsheet No 93. London: BMA/ACP, 1980.

11 Lewis PW, Raine DN, Kennedy JF. Recognition of the mucopolysaccharidoses by four screening tests, including a refinement of the albumin turbidity test, and their differentiation by electrophoretic separation of urinary glycosaminoglycans. Ann Clin Biochem 1974;11:67-71.

12 Pennock CA, White F, Wharton BA. CPC precipitable uronic acid: creatinine ratio in random urine samples collected from normal children. Acta Paediatr Scand 1972;61:125-7.

Requests for reprints to: Dr J M Rattenbury, Department of Chemical Pathology, Children's Hospital, Western Bank, Sheffield S10 2TH, England. 